\title{
Maximum Torque-per-Amp Control for Traction IM Drives: Theory and Experimental Results
}

\author{
Serhiy Bozhko ${ }^{1}$, Serhii Dymko ${ }^{2}$, Serhii Kovbasa ${ }^{2}$,Sergei Peresada ${ }^{2}$, \\ ${ }^{1}$ Faculty of Engineering, University of Nottingham, University Park, Nottingham NG7 2RD, United Kingdom \\ ${ }^{2}$ Department Electrical Engineering, National Technical University of Ukraine "KPI”, Peremogy av. 37, 03056 Kyiv, Ukraine \\ Corresponding author: serhiy.bozhko@nottingham.ac.uk
}

\begin{abstract}
A novel maximum torque per Ampere (MTPA) controller for induction motor (IM) drives is presented. It is shown to be highly suited to applications that do not demand an extremely fast dynamic response, for example electric vehicle drives. The proposed MTPA field oriented controller guarantees asymptotic torque (speed) tracking of smooth reference trajectories and maximises the torque per Ampere ratio when the developed torque is constant or slow varying. An outputfeedback linearizing concept is employed for the design of torque and flux subsystems to compensate for the torque-dependent flux variations required to satisfy the MTPA condition. As a first step, a linear approximation of the IM magnetic system is considered. Then, based on a standard saturated IM model, the nonlinear static MTPA relationships for the rotor flux are derived as a function of the desired torque, and a modified torque-flux controller for the saturated machine is developed. The flux reference calculation method to achieve simultaneously an asymptotic field orientation, torque-flux decoupling and MTPA optimization in steady state is proposed. The method guarantees singularity-free operation and can be used as means to improve stator current transients. Experimental tests prove the accuracy of the control over a full torque range and show successful compensation of the magnetizing inductance variations caused by saturation. The proposed MTPA control algorithm also demonstrates a decoupling of the torque (speed) and flux dynamics to ensure asymptotic torque tracking. In addition, a higher torque per Ampere ratio is achieved together with an improved efficiency of electromechanical energy conversion.
\end{abstract}

Keywords - induction motor, torque, control, tracking, saturation.

\section{INTRODUCTION}

During recent decades there has been a growing trend within many applications to replace Induction Machine (IM) with Permanent Magnet Synchronous Machine (PMSM) due to their higher efficiency, torque and power density [1]. However the cost of PMSM is significantly higher than IM due to the use of rare-earth magnetic materials which have a very limited origin and their cost is continuously increasing. The tendency to reduce the use of expensive rare-earth magnets in industrial and electrical traction drives has driven a renewed interest for research into advanced design and control concepts for IM [2],[3]. Field-oriented vector control (FOC) [4], advanced FOC [5] and Direct Torque Control (DTC) [6] of IMs have been established a de-facto industrial standard for high and medium dynamic performance applications. Vector controlled and DTC IM drives typically operate with constant flux magnitude even at low values of produced torque which results in good dynamic performance. However conversely, the machine efficiency and power factor can be low, especially for small torque values.

The IM torque is a product of the flux amplitude and the torque component of the stator current, providing a degree of freedom for reduction of the power conversion losses or for attaining other performance criteria. The optimization techniques typically reported in publications adjust the flux level as a function of the electromagnetic torque using various optimization procedures. The flux regulation restricts the drive dynamic performance hence this approach can be employed in applications not requiring an extremely fast response, for example, in electric vehicle drives where the drive only operates at rated torque for a limited proportion of time. A number of control strategies to optimize different performance objectives are known [2], [3], [7]-[11], including minimization of active and total losses, power factor maximization, MTPA control, maximum torque per voltage control and maximum power transfer. The established optimization methods are designed for steady-state operation (i.e. the drive is operating in constant torque). Dynamic behaviour optimization during torque transient is only considered in very few papers [12], [13].

MTPA control [11] minimizes the stator current for a given machine torque. Maximizing the machine torque by having limited source voltage and inverter current capability improves the electromechanical system performance. This is particularly beneficial for traction systems. Under the MTPA control strategy, the torque controller adjusts the flux reference to increase the efficiency at low loads. As a result of this optimization, the torque per Ampere ratio is maximized and additionally the achievable values of motor efficiency are close to those obtained using the minimum active losses optimization criterion [10], [14]. The basic MTPA control objective is achieved by controlling stator current torque and flux components, expressed in terms of rotor flux reference frame, to be equal. This leads to IM operation with constant slip frequency which is equal to the reciprocal of the rotor time constant. The MTPA relations are derived from the condition of the IM when producing constant electromagnetic torque. A few theoretical results based on vector and scalar control concepts are known: modified field-orientated control [11], non-holonomy approach [15] and voltage frequency control [16]. However, simultaneous control of machine torque and flux results in poor torque dynamics; moreover, these dynamics cannot be specified due to the complexity and nonlinearity of the controlled plant (IM).

For all the optimization techniques above an important issue for variable flux operation is the machine saturation effect. This effect results in varying machine inductances hence the assumption of linear magnetic circuits, common for standard optimization routines, is no longer valid. In addition, algorithms for flux estimation will no longer provide accurate information required for torque and flux controls. For MTPA control these issues have been studied in [17]-[19]. In [17] a modification of [11] is presented using an IM model which accounts for the effects of magnetizing and leakage saturation. The desired stator current amplitude and slip frequency are 
approximated as nonlinear functions of the torque reference. Field oriented control with a standard MTPA approach for speed regulation of electric vehicles is proposed in [18]. Torque and flux components of the stator current references are computed at the base of the MTPA curve as functions of speed controller output, proportional to the motor torque reference. MTPA algorithm [19] based on direct-flux vector control (DFVC) [20] provides fast stator flux regulation using direct axis voltage control within a stator flux oriented reference frame. Fast torque regulation is achieved by controlling the torque component of the stator current vector (quadrature), while the flux current component (direct) is not controlled. An additional control action is needed to limit the stator current amplitude. The flux reference required in order to achieve the MTPA condition in [19] is given by a nonlinear static function of the desired torque. The nonlinear saturation effect is taken into account in [17]-[20] using stored computed or measured data.

At present, published studies address the asymptotic torque regulation problem for constant torque references. However, a complex nonlinear torque-flux dynamic is generated by MTPA optimization [11], [15]-[17] making this approach unsuitable for technological applications where accurate torque tracking control is required, for example, in order to enhance passenger comfort during vehicle motion. Tracking of the smooth references is a more general solution of the torque control problem and can be considered as extension of the fast torque regulation typically achieved with fast flux and torque current subsystems having high gain flux and current controllers [18], [19]. Torque tracking is a necessary requirement in order to successfully track the desired speed trajectories in speed control mode.

This paper addresses the problem of asymptotic torque tracking control with MTPA optimisation for saturated IMs. In [21] this problem was investigated assuming linear magnetic circuits for MTPA optimisation and controller design. This study, in order to improve the torque-flux tracking performance, takes into account the effect of saturation within the controller design.

The key contribution of this paper is a novel torque-flux tracking controller design that simultaneously provides asymptotic torque tracking of the smooth reference trajectories in the whole range of machine torques and tracking of the torque-dependent flux references in order to achieve MTPA optimisation in steady state. Torque-flux decoupling allows the flux reference trajectories to be formulated as a static or dynamic functions of the torque reference hence avoiding a singularity at torque zero-crossing and improving stator current transients. Flux tracking allows to set the initial machine excitation level close to zero hence preserving singularity-free operation. The proposed approach is based on output-feedback linearising control and applied to both indirect and direct (observer based) field orientation. The theoretical findings of this study and the effectiveness of the proposed approach are confirmed by thorough experimental validation. This paper is an expanded and further developed version of the earlier conference paper [22].

The paper is organized as follows. The IM model and control problem formulation are given in Sections II and III. The torque tracking MTPA controllers for linear approximation of the magnetising curve are designed in Section IV. An extension of the MTPA torque-flux controller for saturated IM is given in Section V. The speed controller with MTPA is presented in Section VI. In Section VII the experimental test results are reported followed by the Conclusions of the study.

\section{INDUCTION MACHINE MODEL}

For the purpose of this study the $1 / \lambda$-saturated IM model reported in [23], [24] has been employed. The model assumes that only the magnetizing inductance $\mathrm{L}_{\mathrm{m}}$ is saturated hence the leakage inductances are constant, and neglects the crosssaturation inductance so static and dynamic magnetizing inductances are equal.

The following definitions are used:

- static inductance of the magnetizing circuit:

$$
\mathrm{L}_{\mathrm{m}}\left(\mathrm{i}_{\mathrm{m}}\right) \triangleq \psi_{\mathrm{m}}\left(\mathrm{i}_{\mathrm{m}}\right) / \mathrm{i}_{\mathrm{m}}
$$

where $\psi_{\mathrm{m}}\left(\mathrm{i}_{\mathrm{m}}\right)-$ magnetizing curve, and $\mathrm{i}_{\mathrm{m}}-$ magnetizing current;

- stator and rotor inductances, respectively:

$$
\begin{aligned}
& \mathrm{L}_{1}\left(\mathrm{i}_{\mathrm{m}}\right)=\mathrm{L}_{\mathrm{m}}\left(\mathrm{i}_{\mathrm{m}}\right)+\mathrm{L}_{1 \sigma} \\
& \mathrm{L}_{2}\left(\mathrm{i}_{\mathrm{m}}\right)=\mathrm{L}_{\mathrm{m}}\left(\mathrm{i}_{\mathrm{m}}\right)+\mathrm{L}_{2 \sigma}
\end{aligned}
$$

where $\mathrm{L}_{1 \sigma}=$ const and $\mathrm{L}_{2 \sigma}=$ const are stator and rotor leakage inductances.

Under these assumptions, the two-phase model of saturated IM in an arbitrary rotating reference frame, dq, is given as follows:

$$
\begin{aligned}
& \dot{\omega}=\left(\mathrm{T}-\mathrm{T}_{\mathrm{L}}\right) / \mathrm{J} \\
& \mathrm{T}=\mu_{1 \mathrm{~m}}\left(\psi_{\mathrm{d}} \mathrm{i}_{\mathrm{q}}-\psi_{\mathrm{q}} \mathrm{i}_{\mathrm{d}}\right) \\
& \dot{\mathrm{i}}_{\mathrm{d}}=-\gamma_{\mathrm{m}} \mathrm{i}_{\mathrm{d}}+\omega_{0} \mathrm{i}_{\mathrm{q}}+\alpha_{\mathrm{m}} \beta_{\mathrm{m}} \psi_{\mathrm{d}}+\omega \beta_{\mathrm{m}} \psi_{\mathrm{q}}+\mathrm{u}_{\mathrm{d}} / \sigma_{\mathrm{m}} \\
& \dot{\mathrm{i}}_{\mathrm{q}}=-\gamma_{\mathrm{m}} \mathrm{i}_{\mathrm{q}}-\omega_{0} \mathrm{i}_{\mathrm{d}}+\alpha_{\mathrm{m}} \beta_{\mathrm{m}} \psi_{\mathrm{q}}-\omega \beta_{\mathrm{m}} \psi_{\mathrm{d}}+\mathrm{u}_{\mathrm{q}} / \sigma_{\mathrm{m}} \\
& \dot{\psi}_{\mathrm{d}}=-\alpha_{\mathrm{m}} \psi_{\mathrm{d}}+\alpha_{\mathrm{m}} \mathrm{L}_{\mathrm{m}}\left(\mathrm{i}_{\mathrm{m}}\right) \mathrm{i}_{\mathrm{d}}+\omega_{2} \psi_{\mathrm{q}} \\
& \dot{\psi}_{\mathrm{q}}=-\alpha_{\mathrm{m}} \psi_{\mathrm{q}}+\alpha_{\mathrm{m}} \mathrm{L}_{\mathrm{m}}\left(\mathrm{i}_{\mathrm{m}}\right) \mathrm{i}_{\mathrm{q}}-\omega_{2} \psi_{\mathrm{d}} \\
& \dot{\varepsilon}_{0}=\omega_{0}
\end{aligned}
$$

where $\mathrm{u}_{\mathrm{d}}, \mathrm{u}_{\mathrm{q}}$ are stator voltage components (here and throughout the paper subscripts $d$ and $q$ denote vector variable components in the dq reference frame), $i_{d}, i_{q}$ are stator currents, $\psi_{\mathrm{d}}, \psi_{\mathrm{q}}$ define the rotor flux, $\omega$ is the rotor speed, $\mathrm{T}$ is the electromagnetic torque, $T_{L}$ is the load torque and $\varepsilon_{0}$ is the angular position of the dq reference frame with respect to a fixed stator reference frame $(a b)$ in which physical variables are defined. Slip frequency is defined as $\omega_{2}=\omega_{0}-\omega$, and $\mathrm{J}$ is the total rotor inertia. One pole pair is assumed without loss of generality. In the model (3) constants (all positive) related to IM electrical parameters are given by:

$$
\begin{aligned}
& \alpha_{\mathrm{m}}=\mathrm{R}_{2} / \mathrm{L}_{2}\left(\mathrm{i}_{\mathrm{m}}\right) \\
& \beta_{\mathrm{m}}=\mathrm{L}_{\mathrm{m}}\left(\mathrm{i}_{\mathrm{m}}\right) /\left[\mathrm{L}_{2}\left(\mathrm{i}_{\mathrm{m}}\right) \sigma_{\mathrm{m}}\right] \\
& \gamma_{\mathrm{m}}=\mathrm{R}_{1} \sigma_{\mathrm{m}}^{-1}+\alpha_{\mathrm{m}} \beta_{\mathrm{m}} \mathrm{L}_{\mathrm{m}}\left(\mathrm{i}_{\mathrm{m}}\right) \\
& \sigma_{\mathrm{m}}=\mathrm{L}_{1}\left(\mathrm{i}_{\mathrm{m}}\right)-\mathrm{L}_{\mathrm{m}}^{2}\left(\mathrm{i}_{\mathrm{m}}\right) / \mathrm{L}_{2}\left(\mathrm{i}_{\mathrm{m}}\right) \\
& \mu_{1 \mathrm{~m}}=3 \mathrm{~L}_{\mathrm{m}}\left(\mathrm{i}_{\mathrm{m}}\right) /\left[2 \mathrm{~L}_{2}\left(\mathrm{i}_{\mathrm{m}}\right)\right]
\end{aligned}
$$

Here $R_{1}, R_{2}$ are stator and rotor resistances respectively. The index $\mathrm{m}$ in (4) is used to denote the parameter's dependency on magnetizing current $i_{m}$.

It is important to note that the traditional model of the nonsaturated IM can be derived from (3), assuming linear 
magnetic circuits, i.e. not depending on $i_{m}$, hence the following applies: $\mathrm{L}_{\mathrm{m}}\left(\mathrm{i}_{\mathrm{m}}\right)=\mathrm{L}_{\mathrm{m}}$ where $\mathrm{L}_{\mathrm{m}}=$ const $\quad$ the machine magnetizing inductance at the rated flux, and $\alpha_{\mathrm{m}}=\alpha, \beta_{\mathrm{m}}=\beta$, $\gamma_{\mathrm{m}}=\gamma, \sigma_{\mathrm{m}}=\sigma, \mu_{1 \mathrm{~m}}=\mu_{1}$.

\section{CONTROL Problem Statement}

In this study the torque tracking control problem is formulated as follows:

Consider the IM model (3) and assume that:

A1. The stator currents and rotor speed are available for measurement. All motor parameters are known and constant. All saturation-dependent parameters are known function of a magnetizing current.

A2. The torque reference trajectory $\mathrm{T}^{*}$ is a smooth and bounded function together with its first and second time derivatives.

Under these assumptions, the control problem is to design a torque controller which guarantees the following control objectives:

CO1. Asymptotic torque tracking with all internal signals bounded, i.e.

$$
\lim _{\mathrm{t} \rightarrow \infty} \tilde{\mathrm{T}}=0
$$

where $\tilde{\mathrm{T}}=\mathrm{T}-\mathrm{T}^{*}$ is torque tracking error; state:

CO2. Maximization of Torque per Ampere ratio in steady

$$
\max \left(T / \mathrm{I}_{1}\right), \mathrm{I}_{1}=\sqrt{\mathrm{i}_{\mathrm{d}}^{2}+\mathrm{i}_{\mathrm{q}}^{2}}
$$

where $I_{1}-$ is a stator current magnitude.

CO3. Asymptotic field orientation, i.e.

$$
\lim _{\mathrm{t} \rightarrow \infty} \psi_{\mathrm{q}}=0
$$

The following sections report the proposed solution to the formulated control problem.

\section{TORQUE CONTROLLER DESIGN FOR LINEAR MAGNETIZING CURVE (MTPAL)}

This Section deals with the design of torque-flux controllers that simultaneously guarantee an asymptotic tracking of the permissible torque references, the rotor flux orientation and flux-torque decoupling. Flux tracking allows:

a) to design the flux reference trajectories as a static or dynamic function of desired torque in order to achieve the MTPA condition in steady state and improve stator current transients;

b) to avoid singularity (when flux is zero) selecting the flux reference and controller initialization.

At the initial stage two controllers assuming linear magnetic circuits were designed; an MTPA controller with indirect field orientation and an MTPA controller with direct field orientation employing a rotor flux observer. For both these cases current-fed control is assumed. Following these, a fullorder direct field-oriented MTPA control is proposed, including proof of its asymptotic stability.

\section{A. Indirect field orientation for current-fed IM}

Indirect field orientation allows for vector control design to achieve high IM drive performance. In standard configuration with independent torque and flux references it is simpler in comparison to direct orientation methods from the point of view of practical implementation.

The proposed solution exploits the concept of indirect fieldoriented IM control [20] with flux control given by:

$$
\begin{aligned}
& \dot{\varepsilon}_{0}=\omega_{0}=\omega+\alpha \mathrm{L}_{\mathrm{m}} \frac{\mathrm{i}_{\mathrm{q}}}{\psi^{*}} \\
& \mathrm{i}_{\mathrm{d}}=\frac{1}{\alpha \mathrm{L}_{\mathrm{m}}}\left(\alpha \psi^{*}+\dot{\psi}^{*}\right)
\end{aligned}
$$

where $\psi^{*}>0$ is a smooth flux reference trajectory. The controller (8)-(9), for the current-fed condition, guarantees that both flux magnitude tracking (10) and asymptotic field orientation (11) are globally achieved:

$$
\begin{aligned}
& \lim _{\mathrm{t} \rightarrow \infty} \mathrm{e}_{\mathrm{d}}=0 \\
& \lim _{\mathrm{t} \rightarrow \infty} \mathrm{e}_{\mathrm{q}}=0
\end{aligned}
$$

where $e_{d}$ and $e_{q}$ are flux tracking error expressed in terms of the reference dq frame:

$$
e_{d}=\psi_{d}-\psi^{*}, e_{q}=\psi_{q}
$$

The torque tracking error equation can be derived using ( 3 ) and definitions (5), (12) as follows:

$$
\tilde{\mathrm{T}}=\mu_{1}\left[\psi^{*} \mathrm{i}_{\mathrm{q}}+\mathrm{e}_{\mathrm{d}} \mathrm{i}_{\mathrm{q}}-\mathrm{e}_{\mathrm{q}} \mathrm{i}_{\mathrm{d}}\right]-\mathrm{T}^{*}
$$

from which a feedback-linearising torque controller can be constructed as:

$$
\mathrm{i}_{\mathrm{q}}=\mathrm{T}^{*} / \mu_{1} \psi^{*}
$$

Equations (8), (9) and (14) define the indirect field-orientation based flux-torque controller. Under the action of the proposed controller the error dynamics can be derived as:

$$
\begin{aligned}
& \tilde{\mathrm{T}}=\mu_{1}\left(\mathrm{e}_{\mathrm{d}} \mathrm{i}_{\mathrm{q}}-\mathrm{e}_{\mathrm{q}} \mathrm{i}_{\mathrm{d}}\right) \\
& \dot{\mathrm{e}}_{\mathrm{d}}=-\alpha \mathrm{e}_{\mathrm{d}}+\omega_{2} \mathrm{e}_{\mathrm{q}} \\
& \dot{\mathrm{e}}_{\mathrm{q}}=-\alpha \mathrm{e}_{\mathrm{q}}-\omega_{2} \mathrm{e}_{\mathrm{d}}
\end{aligned}
$$

From boundness of flux and torque references and their derivatives it follows that currents in (9) and (14) are also bounded. The equilibrium point $\left(e_{d}, e_{q}\right)=0$ is globally exponentially stable, and consequently the torque error according to the first equation in (15) goes exponentially to zero, i.e. $\lim _{\mathrm{t} \rightarrow \infty} \tilde{\mathrm{T}}=0$. From the analysis above it follows that torque tracking (CO1), the field orientation (CO3) and flux reference $\left(\psi^{*}>0\right)$ tracking are achieved. It should be noted that asymptotic indirect field orientation and consequently torque and flux decoupling for time-varying flux references are possible only if flux tracking is achieved. Condition $\psi^{*}>0$ guarantees that controller is free of singularities.

\section{B. Direct field orientation for current-fed IM}

In this subsection direct field-oriented torque-flux tracking control employing an asymptotic rotor flux observer is presented.

The reduced-order flux observer for a linear case of (3) is defined as: 


$$
\begin{aligned}
& \dot{\hat{\psi}}=-\alpha \hat{\psi}+\alpha \mathrm{L}_{\mathrm{m}} \mathrm{i}_{\mathrm{d}}, \\
& \dot{\varepsilon}_{0}=\omega_{0}=\omega+\frac{\alpha \mathrm{L}_{\mathrm{m}} \mathrm{i}_{\mathrm{q}}}{\hat{\psi}}
\end{aligned}
$$

where $\hat{\psi}$ is an observed flux value. This observer guarantees [21] that the flux estimation errors

$$
\begin{aligned}
& \tilde{\psi}_{\mathrm{d}}=\psi_{\mathrm{d}}-\hat{\psi}, \\
& \tilde{\psi}_{\mathrm{q}}=\psi_{\mathrm{q}}
\end{aligned}
$$

decay exponentially to zero provided $\hat{\psi}>0$. Using (17), the torque error equation can be found as follows:

$$
\tilde{\mathrm{T}}=\mu_{1} \widetilde{\psi}_{\mathrm{d}} \mathrm{i}_{\mathrm{q}}+\mu_{1} \hat{\psi}_{\mathrm{q}}-\mu_{1} \tilde{\psi}_{\mathrm{q}} \mathrm{i}_{\mathrm{d}}-\mathrm{T}^{*},
$$

from which a feedback-linearising torque controller can be constructed as:

$$
\mathrm{i}_{\mathrm{q}}=\mathrm{T}^{*} / \mu_{1} \hat{\psi} .
$$

Using (3), (17), (18) and (19), the torque-flux error dynamic is derived as

$$
\begin{aligned}
& \tilde{\mathrm{T}}=\mu_{1}\left(\tilde{\Psi}_{\mathrm{d}} \frac{\mathrm{T}^{*}}{\mu_{1} \hat{\psi}}-\tilde{\Psi}_{\mathrm{q}} \mathrm{i}_{\mathrm{d}}\right) \\
& \dot{\tilde{\Psi}}_{\mathrm{d}}=-\alpha \tilde{\Psi}_{\mathrm{d}}+\omega_{2} \tilde{\Psi}_{\mathrm{q}} \\
& \dot{\tilde{\Psi}}_{\mathrm{q}}=-\alpha \tilde{\Psi}_{\mathrm{q}}-\omega_{2} \tilde{\Psi}_{\mathrm{d}}
\end{aligned}
$$

For bounded $\mathrm{T}^{*}$ and $\hat{\psi}(\mathrm{t})>0$, the current $\mathrm{i}_{\mathrm{q}}$ is bounded as well. In addition, the subsystem (21)-(22) is globally exponentially stable:

$$
\lim _{\mathrm{t} \rightarrow \infty}\left(\tilde{\psi}_{\mathrm{d}}, \tilde{\psi}_{\mathrm{q}}\right)=0
$$

Hence, the torque error $\tilde{T}$ in (20) exponentially decays to zero if $i_{d}$ is bounded.

In order to provide the specified estimated flux $\hat{\psi}(\mathrm{t})$ dynamics the following PI controller is employed to control estimated flux magnitude in (16):

$$
\begin{aligned}
& \mathrm{i}_{\mathrm{d}}=\frac{1}{\alpha \mathrm{L}_{\mathrm{m}}}\left(\alpha \psi^{*}+\dot{\psi}^{*}-\mathrm{k}_{\psi \mathrm{p}} \tilde{\psi}-\mathrm{x}_{\psi}\right) \\
& \dot{\mathrm{x}}_{\psi}=\mathrm{k}_{\psi \mathrm{i}} \tilde{\psi}
\end{aligned}
$$

where: $\tilde{\psi}=\hat{\psi}-\psi^{*}$ is flux (estimated) tracking error; $\mathrm{k}_{\psi \mathrm{p}}$ and $\mathrm{k}_{\psi \mathrm{i}}$ are the controller proportional and integral gains respectively. From (16) and (24), the error dynamic can be derived as

$$
\begin{aligned}
& \dot{\tilde{\psi}}=-\left(\alpha+\mathrm{k}_{\psi \mathrm{p}}\right) \tilde{\psi}-\mathrm{x}_{\psi} \\
& \dot{\mathrm{x}}_{\psi}=\mathrm{k}_{\psi \mathrm{i}} \tilde{\psi}
\end{aligned}
$$

If $\tilde{\psi}(0)=0$ then all solutions of $(25) \tilde{\psi}(\mathrm{t}) \equiv 0 \forall \mathrm{t} \geq 0$. From this condition follows that $\hat{\psi}(\mathrm{t})=\psi^{*}(\mathrm{t})>0, \mathrm{i}_{\mathrm{d}}$ is bounded, and consequently $\lim _{t \rightarrow \infty}(\tilde{\mathrm{T}}, \tilde{\psi})=0$. The analysis above proofs that control objectives $(\mathrm{CO} 1),(\mathrm{CO} 3)$, flux reference $\left(\psi^{*}>0\right)$ tracking and flux vector estimation are globally achieved. From condition $\hat{\psi}(\mathrm{t})=\psi^{*}(\mathrm{t})>0$ it also follows that controller (16), (19) is free of singularities.

Note that asymptotic direct field orientation does not require flux and torque tracking properties. Nevertheless, for small $\psi^{*}>0$ (needed for MTPA optimization) and fast references the errors in flux regulation become critical. The flux tracking guarantees that $\tilde{\psi}(\mathrm{t}) \equiv 0 \forall \mathrm{t} \geq 0$, hence singularities are avoided.

\section{Flux reference selection to achieve MTPA condition}

The torque-flux tracking capabilities of the controllers (8),(9), (14) and (16), (19), (24) allow the selection of flux reference trajectories such that the maximization of Torque per Ampere ratio in steady state $(\mathrm{CO} 2)$ is achieved. MTPA conditions for all flux references $\psi^{*}>0$ in (9) and (24) are:

a) derivative $\dot{\psi}^{*}$ is bounded

b) flux reference in steady state satisfies the following:

$$
\bar{\psi}^{*}=\psi_{0}^{*}+\mathrm{L}_{\mathrm{m}}\left|\overline{\mathrm{i}}_{\mathrm{q}}\right|
$$

where $\left|\bar{i}_{\mathrm{q}}\right|$ is the steady state value of $\left|i_{\mathrm{q}}\right|$ and $\psi_{0}^{*}>0$ is a small flux to avoid singularities in (8), (14), (16) and (19) at zero torque reference $\mathrm{T}^{*}=0$.

From (26), (9), and (24) it follows that the MTPA ratio in steady state is achieved under the condition:

$$
\overline{\mathrm{i}_{\mathrm{d}}}=\left|\overline{\mathrm{i}}_{\mathrm{q}}\right|+\psi_{0}^{*} / \mathrm{L}_{\mathrm{m}}
$$

where $\bar{i}_{d}$ is the steady state value of $i_{d}$ and $\psi_{0}{ }^{*} / L_{m}$ is a small constant. Note that the known result [11] is a subset of the derived conditions (26), (27).

According to assumption A2, the torque reference $\mathrm{T}^{*}$ and its derivative are bounded, hence the flux reference trajectory $\psi^{*}>0$ may be computed directly from (26) and (14) with $\bar{\psi}^{*}=\psi^{*}, \overline{\mathrm{i}}_{\mathrm{q}}=\mathrm{i}_{\mathrm{q}}$ as a solution of the quadratic equation::

$$
\psi^{*}=\frac{\psi_{0}^{*}}{2}+\xi_{\mathrm{T}}, \xi_{\mathrm{T}}=\sqrt{\frac{\psi_{0}^{* 2}}{4}+\frac{2}{3} \mathrm{~L}_{2}\left|\mathrm{~T}^{*}\right|} .
$$

The time derivative of $\psi^{*}$ can be found as:

$$
\dot{\psi}^{*}=\frac{\mathrm{L}_{2} \dot{\mathrm{T}}^{*} \operatorname{sign}\left(\mathrm{T}^{*}\right)}{3 \xi_{\mathrm{T}}} .
$$

From (9), (24) and stability analysis above it follows that the selected flux reference trajectory (28) satisfies the steady state condition (27) and has a bounded derivative. Hence, all three control objectives are successfully achieved: torque tracking (CO1), field orientation (CO3) and maximization of the torque per Ampere ratio in steady state (CO2).

Based on the discussion above, a more general solution to the flux reference trajectory selection can be proposed. The flux control plant is $1^{\text {st }}$ order (current feed condition) while the torque subsystem has no dynamics. Hence, some filtering of the flux reference is required in order to reduce spikes in stator current flux component $i_{d}$ during transients. One possible solution for flux reference filtering directly follows from (9) and (14) (for direct field orientation - from (24) and (19) if $\tilde{\psi}(\mathrm{t}) \equiv 0)$ as an output of the nonlinear dynamic system:

$$
\dot{\psi}^{*}=-\alpha \psi^{*}+\frac{2}{3} \frac{\alpha \mathrm{L}_{2}\left|\mathrm{~T}^{*}\right|}{\psi^{*}}+\alpha \psi_{0}^{*} .
$$

In a more general case the flux reference is defined as an output of the smoothing filter which processes the reference $\psi^{r}$ defined by (28). Such a filter allows the reconstruction of the 
flux reference derivatives hence reducing the computational burden. For example, a $2^{\text {nd }}$-order filter can be employed:

$$
\begin{aligned}
& \psi^{*}=\zeta, \\
& \dot{\zeta}^{2} \zeta_{1}, \\
& \dot{\zeta}_{1}=-\mathrm{k}_{1} \zeta_{1}-\mathrm{k}_{2} \zeta+\mathrm{k}_{2} \psi^{\mathrm{r}}
\end{aligned}
$$

where $\mathrm{k}_{1}$ and $\mathrm{k}_{2}$ are filter tuning gains. Selecting unity damping $\mathrm{k}_{2}=\mathrm{k}_{1}^{2} / 4$ the condition $\psi^{*}>0$ is satisfied. The filter reconstructs the $1^{\text {st }}$ and $2^{\text {nd }}$ derivatives of the flux reference $\psi^{*}$ (the $2^{\text {nd }}$ derivative is required for the full-order control to be considered in the next subsection). If required, the filter dynamic can be designed as fast as possible by selection of high gains. Large enough values of $\mathrm{k}_{1}$ and $\mathrm{k}_{2}$ will provide, according to singular perturbation theory [26], the flux reference (28).

The resulting control system, with the MTPA controller, has a single input, namely the torque reference $\mathrm{T}^{*}$, and three outputs: the torque $\mathrm{T}$, the rotor flux magnitude and its angular position. It should be noted that controllers based on direct and indirect field orientation will provide the same dynamic performance for the same reference trajectories.

In the next subsection the reduced order solution is extended to a full-order algorithm in preparation for the subsequent design of an MTPA controller for a saturated machine within Section V.

\section{Full order controller design}

In the Sections above it was assumed that the machine is current-fed, i.e. $\mathrm{i}_{\mathrm{d}}$ and $\mathrm{i}_{\mathrm{q}}$ currents are the control signals. Considering practical IM drive implementations, the currents in (3) represent only their desired dynamics: the reference trajectories $\mathrm{i}_{\mathrm{d}}{ }^{*}$ and $\mathrm{i}_{\mathrm{q}}{ }^{*}$ are given by (9), (14) for indirect field orientation and by (24), (19) for direct field orientation. These trajectories are the references for the inner current control loops. As the PI controllers typically employ high gains in order to achieve a very fast response this justifies the assumption that the current dynamic in (3) can be neglected. As a result, appropriate current tracking controllers must be designed.

In this Section, the full-order torque controller is derived from the proposed reduced-order controller by the addition of current control loops which use the back-stepping procedure [27]. For both indirect and direct field oriented controllers the design procedure is similar. The procedure is demonstrated below for the direct field oriented strategy.

The current loops controls are designed as follows:

$$
\mathrm{u}_{\mathrm{d}}=\sigma\left(\gamma \mathrm{i}_{\mathrm{d}}^{*}-\omega_{0} \mathrm{i}_{\mathrm{q}}-\alpha \beta \hat{\psi}+\dot{\mathrm{i}}_{\mathrm{d}}^{*}-\mathrm{k}_{\mathrm{ipd}} \tilde{\mathrm{i}}_{\mathrm{d}}\right)
$$

and

$$
\begin{aligned}
& \mathrm{u}_{\mathrm{q}}=\sigma\left(\gamma \mathrm{i}_{\mathrm{q}}^{*}+\omega_{0} \mathrm{i}_{\mathrm{d}}+\beta \omega \hat{\psi}+\dot{\mathrm{i}}_{\mathrm{q}}^{*}-\mathrm{k}_{\mathrm{ipq}} \tilde{\mathrm{i}}_{\mathrm{q}}+\mathrm{x}_{\mathrm{q}}\right) \\
& \dot{\mathrm{x}}_{\mathrm{q}}=-\mathrm{k}_{\mathrm{iiq}} \tilde{\mathrm{i}}_{\mathrm{q}}
\end{aligned}
$$

where $\tilde{i}_{d}=i_{d}-i_{d}^{*}$ and $\tilde{i}_{q}=i_{q}-i_{q}^{*}$ are current tracking errors, $\mathrm{k}_{\mathrm{ipd}}, \mathrm{k}_{\mathrm{ipq}}$ are the current controller's proportional gains, $\mathrm{k}_{\mathrm{iq}}$ is the integral gain and $\mathrm{x}_{\mathrm{q}}$ is the integral component of the q-axis current controller. It should be noted that the current reference derivatives in (32), (33) are known functions of $\dot{\mathrm{T}}^{*}$ and $\ddot{\mathrm{T}}^{*}$ according to assumption $\mathrm{A} 2$ above.
Consider the modified flux observer given by

$$
\begin{aligned}
& \dot{\hat{\psi}}=-\alpha \hat{\psi}+\alpha \mathrm{L}_{\mathrm{m}} \mathrm{i}_{\mathrm{d}} \\
& \dot{\varepsilon}_{0}=\omega_{0}=\omega+\frac{\alpha \mathrm{L}_{\mathrm{m}} \mathrm{i}_{\mathrm{q}}}{\hat{\psi}}+\frac{\gamma_{1} \beta \omega \tilde{\mathrm{i}}_{\mathrm{d}}}{\hat{\psi}}
\end{aligned}
$$

where $\gamma_{1}>0$ is the observer correction gain. It is important to note that the correction term $\gamma_{1} \beta \omega \tilde{i}_{d} / \hat{\psi}$ provides the closed loop properties and therefore the observer is robust with respect to the variation in rotor resistance variations at nonzero machine speed [28].

From (3), (32) - (34) the system error dynamic is defined by three subsystems:

- flux estimation subsystem:

$$
\begin{aligned}
& \dot{\tilde{\Psi}}_{\mathrm{d}}=-\alpha \tilde{\Psi}_{\mathrm{d}}+\omega_{2} \tilde{\Psi}_{\mathrm{q}} \\
& \dot{\tilde{\Psi}}_{\mathrm{q}}=-\alpha \tilde{\Psi}_{\mathrm{q}}-\omega_{2} \tilde{\Psi}_{\mathrm{d}}-\gamma \beta \omega \tilde{\mathrm{i}}_{\mathrm{d}} \\
& \dot{\tilde{\mathrm{i}}}_{\mathrm{d}}=-\mathrm{k}_{\mathrm{id}} \tilde{\mathrm{i}}_{\mathrm{d}}+\alpha \beta \tilde{\Psi}_{\mathrm{d}}+\beta \omega \tilde{\Psi}_{\mathrm{q}}
\end{aligned}
$$

- estimated flux regulation subsystem:

$$
\begin{aligned}
& \dot{\tilde{\psi}}=-\left(\alpha+\mathrm{k}_{\psi \mathrm{p}}\right) \tilde{\psi}-\mathrm{x}_{\psi}+\alpha \mathrm{L}_{\mathrm{m}} \tilde{\mathrm{i}}_{\mathrm{d}} \\
& \dot{\mathrm{x}}_{\psi}=\mathrm{k}_{\psi \mathrm{i}} \tilde{\psi}
\end{aligned}
$$

- torque current regulation subsystem

$$
\begin{aligned}
& \dot{\overrightarrow{\mathrm{i}}}_{\mathrm{q}}=-\mathrm{k}_{\mathrm{iq}} \tilde{\mathrm{i}}_{\mathrm{q}}+\alpha \beta \tilde{\psi}_{\mathrm{q}}-\beta \omega \tilde{\psi}_{\mathrm{d}}+\mathrm{x}_{\mathrm{q}} \\
& \dot{\mathrm{x}}_{\mathrm{q}}=-\mathrm{k}_{\mathrm{iiq}} \tilde{\mathrm{i}}_{\mathrm{q}}
\end{aligned}
$$

where $\mathrm{k}_{\mathrm{id}}=\gamma+\mathrm{k}_{\mathrm{ipd}}, \mathrm{k}_{\mathrm{iq}}=\gamma+\mathrm{k}_{\mathrm{ipq}}$.

In order to investigate the stability of the system (35)-(37) the following quadratic form of the flux subsystem (35) must first be considered

$$
\mathrm{V}=\frac{1}{2}\left[\tilde{\psi}_{\mathrm{d}}^{2}+\tilde{\psi}_{\mathrm{q}}^{2}+\gamma_{1} \tilde{\mathrm{i}}_{\mathrm{d}}^{2}\right]>0
$$

The time derivative of (38) along the trajectories (35) can be derived as follows:

$$
\dot{\mathrm{V}}=-\alpha \tilde{\psi}_{\mathrm{d}}^{2}-\alpha \tilde{\psi}_{\mathrm{q}}^{2}-\gamma_{1} \mathrm{k}_{\mathrm{id}} \tilde{\mathrm{i}}_{\mathrm{d}}^{2}+\gamma_{1} \alpha \beta \tilde{\mathrm{i}}_{\mathrm{d}} \tilde{\psi}_{\mathrm{d}}
$$

Under the condition

$$
\mathrm{k}_{\mathrm{id}}>\gamma_{1} \alpha \beta^{2} / 4
$$

the form of (38) becomes a Lyapunov function satisfying conditions

$$
\mathrm{V}>0, \dot{\mathrm{V}}<0
$$

Hence, according to Lyapunov stability criteria it can be concluded that the equilibrium point

$$
\left(\tilde{\Psi}_{\mathrm{d}}, \tilde{\Psi}_{\mathrm{q}}, \tilde{\mathrm{i}}_{\mathrm{d}}\right)^{\mathrm{T}}=0
$$

is globally exponentially stable. Since the subsystems (35), (36), and (37) are connected in series (illustrated by Fig. 1), the conclusion is that for a bounded speed signal $\omega$ the equilibrium point

$$
\left(\tilde{\psi}_{\mathrm{d}}, \tilde{\Psi}_{\mathrm{q}}, \tilde{\mathrm{i}}_{\mathrm{d}}\right)^{\mathrm{T}}=0,\left(\tilde{\mathrm{i}}_{\mathrm{q}}, \mathrm{x}_{\mathrm{q}}\right)^{\mathrm{T}}=0,\left(\tilde{\psi}, \mathrm{x}_{\psi}\right)^{\mathrm{T}}=0
$$

is globally exponentially stable. This implies that the torque tracking error $\tilde{\mathrm{T}}\left(\mathrm{T}^{*}, \tilde{\mathrm{i}}_{\mathrm{d}}, \tilde{\mathrm{i}}_{\mathrm{q}}, \tilde{\Psi}_{\mathrm{d}}, \tilde{\Psi}_{\mathrm{q}}\right)$ decays exponentially to zero, while also achieving asymptotic field orientation and 
MTPA in steady state. Hence the control objectives (CO1)(CO3) are met.

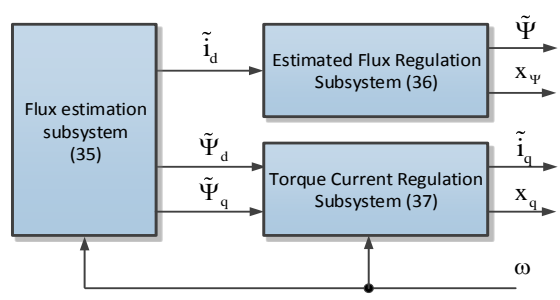

Fig. 1. Error dynamics structure

Tuning parameters of the controller (24), (32)-(35) are: flux controller proportional $\mathrm{k}_{\psi \mathrm{p}}$ and integral $\mathrm{k}_{\psi \mathrm{i}}$ gains, proportional and integral gains $\mathrm{k}_{\mathrm{ipd}}, \mathrm{k}_{\mathrm{ipq}}, \mathrm{k}_{\mathrm{iiq}}$ of current controllers and the observer gain $\gamma_{1}$. Standard tuning for the linear $2^{\text {nd }}-$ order systems (36) and (37) are used, and relation between $\mathrm{k}_{\text {ipd }}$ and $\gamma_{1}$ is given by (40).

It should be noted that the full-order current controllers (32) and (33) require reference current derivatives. These are complex nonlinear expressions which depend on the torque reference trajectory and its $1^{\text {st }}$ and $2^{\text {nd }}$-order time derivatives. When implementing in practical systems, if the required torque trajectories are smooth, it is possible to simplify the current controllers by neglecting these derivatives provided that the current controllers have high gains.

In order to avoid operating the machine in saturation mode the range of $i_{d}$ should be limited such that the flux does not exceed its rated value.

As discussed in Subsection C, tracking performance of the proposed controller provides some freedom in flux reference selection as a dynamic function of desired torque. This feature can be regarded as a mean for current transients optimisation considering only the reference signals $\mathrm{T}^{*}, \mathrm{i}_{\mathrm{d}}{ }^{*}, \mathrm{i}_{\mathrm{q}}{ }^{*}$, and not a full complex system dynamics.

\section{NONLINEAR MTPA TORQUE CONTROL (MTPAS)}

The MTPAL control algorithms designed in Section IV assume linear magnetic circuits. In practice, these are nonlinear (due to the saturation effect) and this can lead to errors in torque control and to deviation from the MTPA condition. This Section proposes direct MTPA vector control considering the non-linearity of the machine magnetising curve in order to avoid the abovementioned issues.

Assuming an ideal rotor flux orientation in steady state, the qaxis component of the magnetizing flux is negligible and the $\mathrm{d}$-axis rotor current is zero [29]. Hence,

$$
\mathrm{i}_{\mathrm{m}}=\mathrm{i}_{\mathrm{d}}, \psi_{\mathrm{m}}=\psi
$$

and the IM torque equation becomes:

$$
\mathrm{T}=\mu_{1 \mathrm{~m}} \psi\left(\mathrm{i}_{\mathrm{d}}\right) \mathrm{i}_{\mathrm{q}}, \psi\left(\mathrm{i}_{\mathrm{d}}\right)=\mathrm{L}_{\mathrm{m}}\left(\mathrm{i}_{\mathrm{d}}\right) \mathrm{i}_{\mathrm{d}}
$$

where $\psi-$ is a rotor flux magnitude. The torque per Ampere ratio can be written as

$$
\rho_{\mathrm{T}}=\mathrm{T} / \mathrm{I}_{1} \text {. }
$$

From (45), the torque component of the stator current is

$$
\mathrm{i}_{\mathrm{q}}=\frac{\mathrm{T}}{\mu_{1 \mathrm{~m}} \mathrm{~L}_{\mathrm{m}}\left(\mathrm{i}_{\mathrm{d}}\right) \mathrm{i}_{\mathrm{d}}}
$$

$$
\rho_{\mathrm{T}}=\mathrm{T} \mu_{1 \mathrm{~m}} \mathrm{~L}_{\mathrm{m}}\left(\mathrm{i}_{\mathrm{d}}\right) \mathrm{i}_{\mathrm{d}}\left(\mathrm{i}_{\mathrm{d}}^{4} \mu_{1 \mathrm{~m}}^{2} \mathrm{~L}_{\mathrm{m}}^{2}\left(\mathrm{i}_{\mathrm{d}}\right)+\mathrm{T}^{2}\right)^{-1 / 2}
$$

Solving the equation

$$
\partial \rho_{\mathrm{T}} / \partial \mathrm{i}_{\mathrm{d}}=0
$$

the following relationship can be derived:

$$
\mathrm{i}_{\mathrm{d}}=\eta_{0}+\eta_{1}(|\mathrm{~T}|)
$$

where $\eta_{0}$ is a small flux current which produces the initial excitation in order to avoid a singularity in the IM control, and $\eta_{1}(0)=0$. Equation (50) will maximize the Torque per Ampere ratio in steady state (when $\mathrm{T}=$ const and assuming $\mu_{1 \mathrm{~m}}=$ const). As an illustrative example, Fig. 2 shows the magnetizing curve $\psi_{\mathrm{m}}\left(\mathrm{i}_{\mathrm{m}}\right)$ as well as the MTPA relations (50) for $i_{\mathrm{d}}$ and optimal flux-torque relation $\psi_{\mathrm{o}}(\mathrm{T})$ (45) calculated for the $50 \mathrm{~kW}$ induction machine in Appendix II.
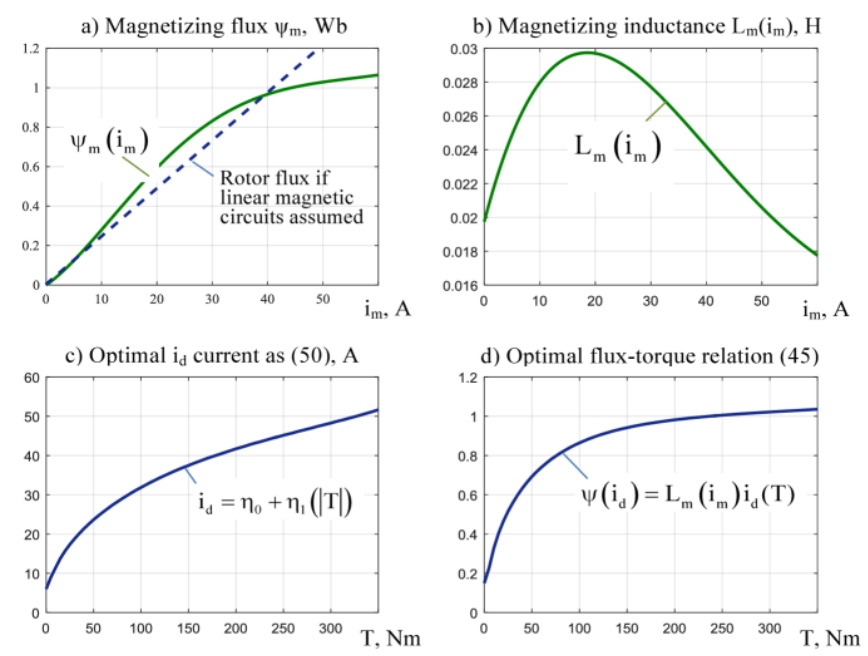

Fig. 2. Magnetizing curve, magnetizing inductance and MTPA relationship for the IM in Appendix II

It is important to note that for saturated IM the standard MTPA relationship $i_{d}=i_{q}[11]$ is no longer valid. In order to maximize the torque per Ampere ratio the flux reference should be adjusted according to the required torque, this is depicted in Fig. 2 for the example machine.

Summarizing this Section, the proposed modified full-order torque control algorithm includes flux controller (24), flux observer (34), torque controller (19), and current controllers (32)-(33). The algorithm takes into account the machine magnetizing curve considering the model (3) constants as given by (4).

From the practical assumption that there is a constant relationship between any pair of $\mathrm{L}_{1}\left(\mathrm{i}_{\mathrm{m}}\right), \mathrm{L}_{2}\left(\mathrm{i}_{\mathrm{m}}\right)$ and $\mathrm{L}_{\mathrm{m}}\left(\mathrm{i}_{\mathrm{m}}\right)$ it can be concluded that:

$$
\begin{aligned}
& \alpha_{\mathrm{m}} \mathrm{L}_{\mathrm{m}}\left(\mathrm{i}_{\mathrm{m}}\right)=\alpha \mathrm{L}_{\mathrm{m}}=\mathrm{const} \\
& \mu_{\mathrm{lm}}=\mu_{1}=\mathrm{const}
\end{aligned}
$$

Asymptotic stability for the proposed torque control system with the modified controller (19), (24), (32)-(34) can be easily shown using the same Lyapunov analysis as presented in previous Section.

The block diagram of the torque control system with the feedback linearising controller (19), (24), (32)-(34) for saturated IM is shown in Fig.3.

hence 


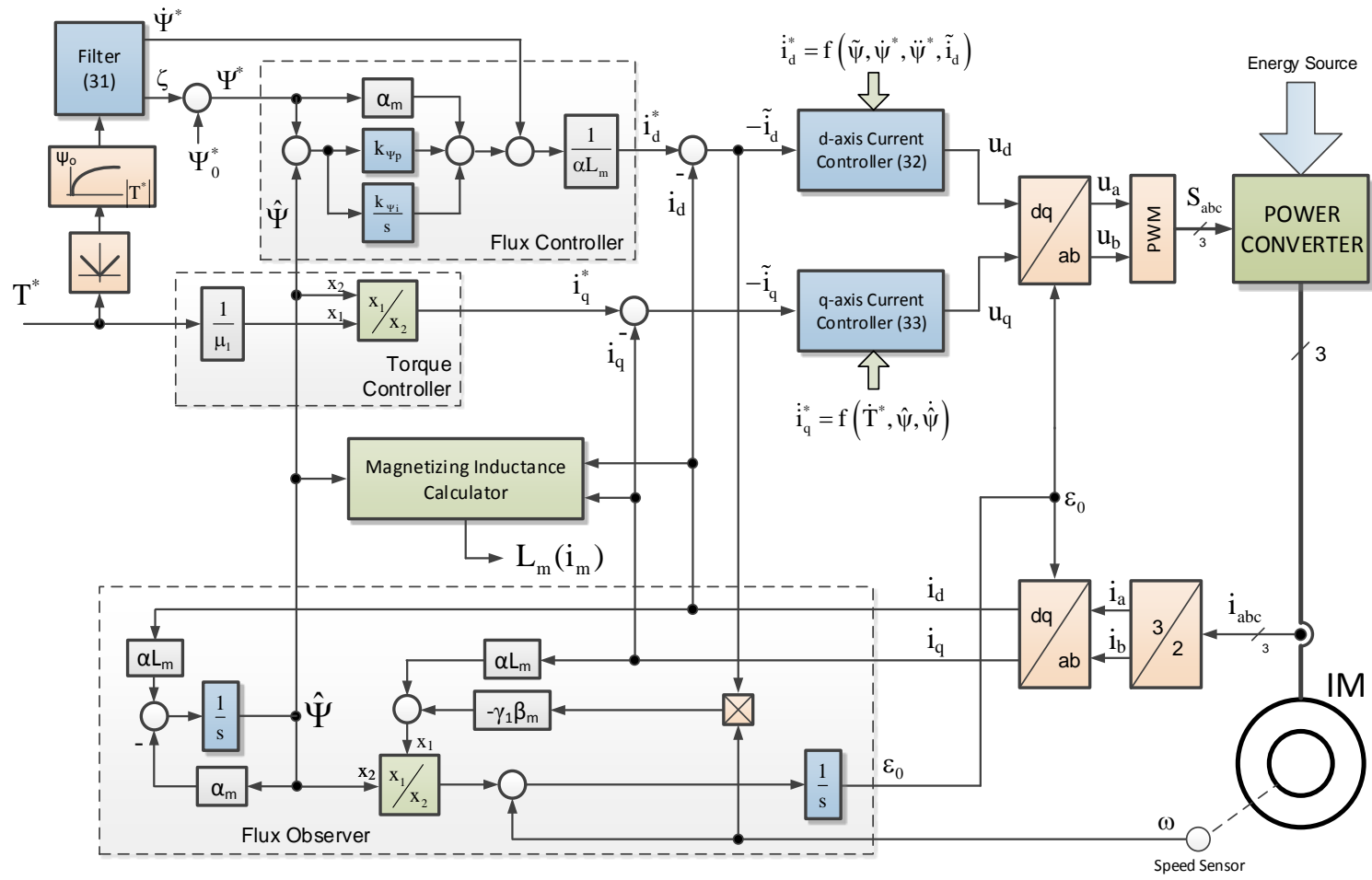

Fig. 3. Block diagram of the torque control system with feedback linearizing controller

\section{SPEED CONTROLLER}

There are little applications in which machine torque control in explicit form is required - for example, in spooling and tensioning drives, electric traction, etc. However in most applications speed control is required, hence this Section considers the design of an external speed controller for the torque control systems designed previously

To begin, assume a smooth and bounded (together with the first two time derivatives) speed reference trajectory $\omega^{*}$ and unknown constant load torque. Under these conditions a speed controller [30], in combination with the above proposed exponentially asymptotically stable torque-flux subsystem, (19), (24), (32)-(34) provides asymptotic speed tracking and constant load torque estimation. The speed controller [30] is given by

$$
\begin{aligned}
& \mathrm{T}^{*}=\mathrm{J}\left(\xi+\dot{\omega}^{*}+\hat{\mathrm{T}}_{\mathrm{L}}\right) \\
& \dot{\hat{\mathrm{T}}}_{\mathrm{L}}=-\mathrm{k}_{\omega \mathrm{i}} \tilde{\omega} \\
& \dot{\xi}=-\frac{\xi}{\tau}-\frac{\mathrm{k}_{\omega \mathrm{p}}}{\tau} \tilde{\omega}
\end{aligned}
$$

where $\tilde{\omega}=\omega-\omega^{*}$ is the speed tracking error, $\hat{\mathrm{T}}_{\mathrm{L}}$ is the load torque estimation component of the constant $T_{\nu} / J, k_{\omega p}$ and $k_{\omega i}$ are speed controller proportional and integral gains respectively, and $\tau$ is the small time constant of the speed filter. In (52) a $1^{\text {st }}$-order linear filter is introduced in order to derive the torque reference derivative that is required for implementation of the torque controller. If the current controller requires a $2^{\text {nd }}-$ order torque reference derivative then a $2^{\text {nd }}$-order linear filter should be employed. The dynamics of speed control loop with speed controller (52) is given by the linear time-invariant third order system [30] which has three tuning parameters $k_{\omega p}, k_{\omega i}, \tau$ to be selected to guarantee asymptotic stability and transient performance.

\section{EXPERIMENTAL VERIFICATION}

This Section reports the results of experiments conducted to support the analytical findings of the previous Sections. The following experiments have been conducted:

- torque tracking performance comparison for different control strategies using the small-power $(5.5 \mathrm{~kW})$ IM drive system detailed in Appendix I

- torque and speed control performance for different control strategies using the medium-power $(50 \mathrm{~kW}) \mathrm{IM}$ traction drive detailed in Appendix II

- comparison study or the dynamic performances of the MTPA controllers during fast torque trajectory tracking.

The experimental results are reported below.

\section{A. Comparison of torque tracking performances}

The task of this experiment was to assess the effect of magnetic saturation on torque tracking performance for three different control strategies, namely:

- Indirect Field-Oriented Control with constant flux (IFOC) [25];

- Full-order MTPA control with linear magnetic curve representation (MTPAL) according to(19), (32)-(34);

- Full-order MTPA control (19), (32)-(34) accounting for IM saturation (MTPAS).

The core idea of this experiment was to demonstrate both the error in torque regulation under MTPA control, if the saturation is not accounted for (MTPAL), and the capability of the MTPAS algorithm to achieve an error margin which is compatible with IFOC (however IFOC does not provide MTPA criteria). 
During these initial tests, the flux controller (24) was removed and the flux current component reference was set as follows:

- for MTPAL control:

$$
\mathrm{i}_{\mathrm{d}}^{*}=\psi_{0}^{*} / \mathrm{L}_{\mathrm{m}}+\left|\mathrm{i}_{\mathrm{q}}^{*}\right|
$$

- for MTPAS control:

$$
\mathrm{i}_{\mathrm{d}}^{*}=\eta_{0}+\eta_{1}\left(\left|\mathrm{~T}^{*}\right|\right)
$$

This methodology also enables utilisation of the closed-loop flux control designed in Section IV. This will be demonstrated within separate tests reported later in this paper. During the initial tests the following test scenario was applied:

- initial interval $(\mathrm{t}<0.5 \mathrm{~s})$ for setting flux reference for MTPA controllers $\left(\psi_{0}{ }^{*}=0.05 \mathrm{~Wb}\right)$; and for setting a rated excitation $\left(\psi^{*}=1.04 \mathrm{~Wb}\right)$ for IFOC strategy

- starting at $\mathrm{t}=0.5 \mathrm{~s}$, an incremental series of torque reference steps was applied as shown in Fig.4(a); the increments are $7 \mathrm{Nm}$ each with the duration $1.45 \mathrm{~s}$ such that at $\mathrm{t}=6.55 \mathrm{~s}$ the torque reference reaches the machine rated value of $35 \mathrm{Nm}$

- at $\mathrm{t}=7.75 \mathrm{~s}$ the torque reference is reduced to zero.

It should be noted that in this experiment the machine rotor speed, when processing of the torque tracking reference, has been stabilized at $10 \mathrm{rad} / \mathrm{s}$ with the speed-controlled load machine.

For each strategy under comparison, the torque tracking error was measured using data from the torque sensor. The results are presented in Fig. 4. It can be concluded from Fig. 4(b), that the IFOC algorithm provides asymptotic torque tracking.

Under MTPAL control (Fig. 4(c)) asymptotic torque tracking is only achieved when the rotor flux is close to its rated value. As the flux reduces, the flux estimation error increases (due to saturation) therefore an error in calculated $i_{q}$ current appears leading to a torque tracking error. For torque reference $7 \mathrm{Nm}$ the error is approximately $15 \%$.
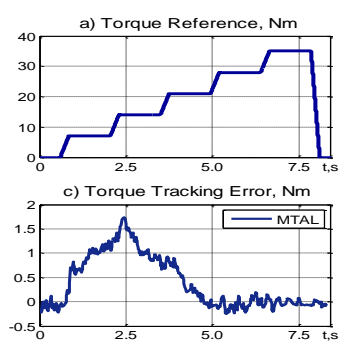

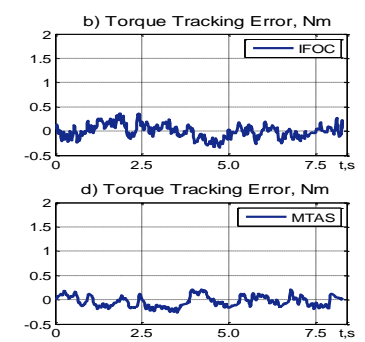

Fig. 4. Torque tracking: (a) torque reference trajectory; (b)- (d) torque errors provided by IFOC, MTPAL and MTPAS controls

The MTPAS control takes into account the effect of magnetic saturation; therefore, the torque tracking error is nearly zero in the full range of torque references, as the results in Fig.4(d) confirm. Hence, the proposed MTPAS controller provides the same accuracy as the IFOC in the whole torque regulation range. From the experimental results in Fig.4 it is clear that the proposed MTPAS strategy successfully compensates for the IM saturation effect.

\section{B. Torque and speed controller performances}

The experiments detailed in this Section investigate the performance of the proposed MTPA strategy for medium- power motors using a 50kW IM-based test rig. The parameters of the test rig are given in Appendix II.

\section{Torque tracking}

The torque tracking performance was tested for IFOC and MTPAS controls. The following scenario was applied:

- initial interval $(\mathrm{t}<1.5 \mathrm{~s})$ for establishing the minimum flux $\psi_{0}=0.02 \mathrm{~Wb}$

- at $\mathrm{t}=1.5 \mathrm{~s}$ a $40 \mathrm{Nm}$ torque reference step ( $13 \%$ of the rated torque) is applied followed by multiple $40 \mathrm{Nm}$ steps, each $3 \mathrm{~s}$ apart, until $200 \mathrm{Nm}$ is reached (67\% of rated value) at $\mathrm{t}=13.5 \mathrm{~s}$, as illustrated by Fig. 5

- at $\mathrm{t}=16.5 \mathrm{~s}$ the torque reference is reduced to zero

- during the interval $20.5 \mathrm{~s}$ to $32 \mathrm{~s}$ the torque reference is a sinusoidal function with magnitude $80 \mathrm{Nm}$ and angular frequency $0.8 \mathrm{rad} / \mathrm{s}$. This trajectory can be regarded as slow in comparison to IM magnetic system dynamics.

For this experiment a DC machine was used as a system load. The machine was set into dynamic braking mode with the excitation winding supplied by the external DC voltage source and the armature connected to the external resistance. This configuration provides the load torque proportional to the rotor speed hence allows to avoid overrun during torque trajectory processing and also to create a small load torque for the speed tracking tests reported in the next subsection.

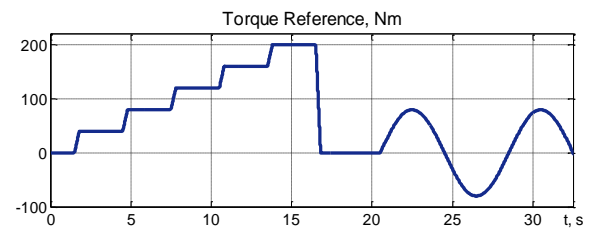

Fig. 5. Torque reference trajectory

The responses of the flux and torque stator current components are depicted in Fig. 6 along with the machine speed. Since the speed trajectories of the IFOC (Fig. 6(a)) and MTPAS controlled (Fig. 6(b)) systems are identical, it can be concluded that the developed torque is equal for both strategies while stator current behaviour is different.

The stator current magnitude, torque per Ampere ratio, machine active power and cumulative consumed energy for both strategies are compared in Fig. 7.
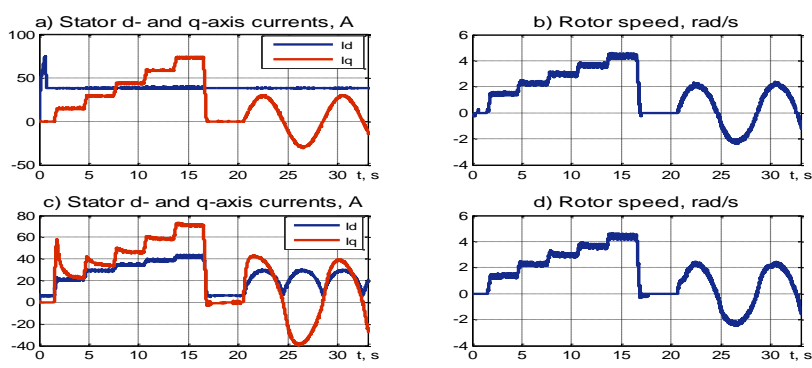

Fig. 6. Stator currents and speed behaviour during torque trajectory tracking: IFOC (top), and MTPAS (bottom)

The results in Figs 6 and 7 clearly demonstrate the advantages of MTPAS control with respect to standard IFOC with constant excitation. The MTPAS controller not only provides a higher torque per Amp ratio but also reduces active power consumption hence improving the drive energy efficiency. During the test scenario detailed above, the IFOC-based 
system consumed $17 \mathrm{~kJ}$ of energy while the MTPAS-based one consumed only $14.4 \mathrm{~kJ}$, i.e. a $16.5 \%$ improvement is achieved.

\section{Speed tracking}

This experiment investigated the performance of the proposed torque controller within an outer speed control loop (52). The speed controller parameters are set as follows:
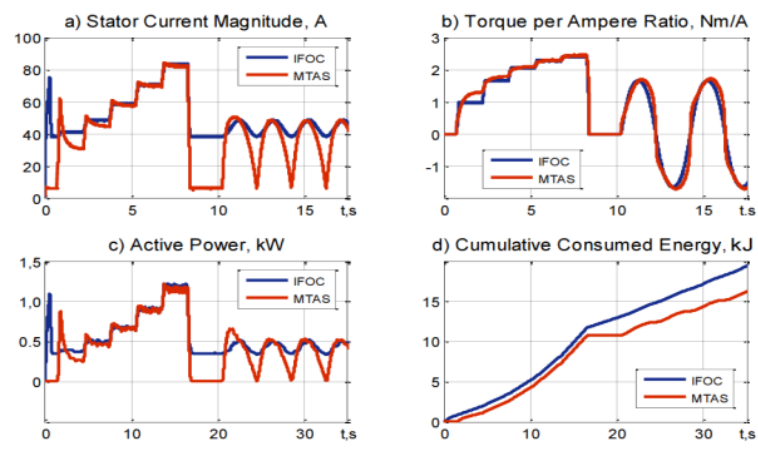

Fig. 7. Transients during torque tracking in the $50 \mathrm{~kW}$ IM traction drive

$\mathrm{k}_{\omega}=60, \mathrm{k}_{\omega \mathrm{i}}=900, \tau=0.002 \mathrm{~s}$. The experiment was conducted using the following scenario:

- during the initial phase $(\mathrm{t}<4.5 \mathrm{~s})$ the motor is operated at very low speed $(0.25 \mathrm{rad} / \mathrm{s})$ in order to avoid the effect of Coulomb friction

- at $\mathrm{t}=4.5 \mathrm{~s}$ the speed reference trajectory shown in Fig. 8(a) was applied. The maximum IM torque during this test was limited to $30 \%$ of its rated value. In this region the proposed MTPA optimization was expected to demonstrate an appreciable effect.

The measured speed tracking error is nearly zero for both controllers, as reported in Fig. 8(b) hence the torque trajectories are regarded identical. Corresponding transients of stator current and rotor flux (estimated) are depicted in Fig.9. It can clearly be seen from Fig.9 that the flux current component in the MTPA system is significantly reduced in comparison to the IFOC system. As a result the stator current magnitude shown in Fig.8(c) is much smaller for the same torque profile.
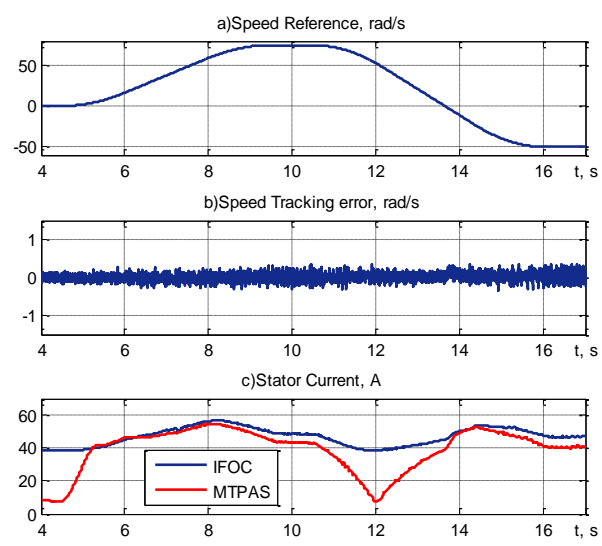

Fig. 8. Speed trajectory tracking by $50 \mathrm{~kW}$ IM traction drive

\section{MTPA controllers with flux regulation}

This test was conducted in order to demonstrate the performance of MTPA control with closed-loop flux regulation (MTPASF) designed in Section IV, with the flux controller (24). This strategy has also been compared against the performance delivered by a DFVC system [19] which represents one of the most advanced solutions to the MPTA control problem. Both experiments were performed with $2.2 \mathrm{~kW}$ induction motor with parameters given in Appendix III. Parameters of this motor are similar to one used in [19]. The following test scenario was applied:

- the machine is preliminary exited with minimum flux $\psi_{0}{ }^{*}=0.05 \mathrm{~Wb}$;
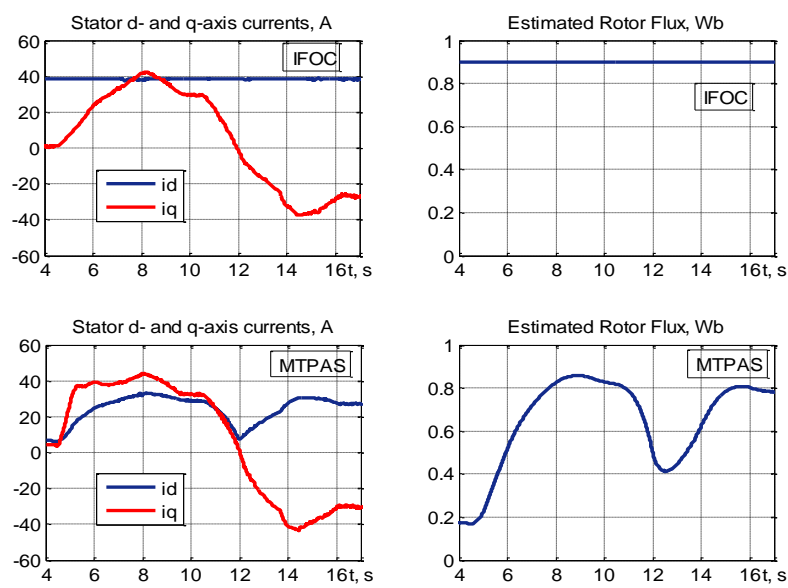

Fig. 9. Stator currents and estimated flux behaviour during speed trajectory tracking: IFOC (top) and MTPAS (bottom)

- then the torque reference trajectory shown in Fig.10 was applied; torque reference starts from zero and reaches $10 \mathrm{Nm}$ (60\% of the rated value) in $0.1 \mathrm{~s}$; at time $\mathrm{t}=0.2 \mathrm{~s}$ there is a reference reversal to $-10 \mathrm{Nm}$ during $0.2 \mathrm{~s}$; and at $\mathrm{t}=0.5 \mathrm{~s}$ the torque reference is reduced to zero. During the experiment the rotor speed was stabilized with the load machine at $20 \mathrm{rad} / \mathrm{s}$.

The applied test conditions are similar to those in [19], but with smaller critical value of $\psi_{0}{ }^{*}=0.05 \mathrm{~Wb}$. The selected torque reference trajectory has been chosen in order to compare the system dynamics provided by the algorithms, including torque zero-crossing, as well as operation in steady-state. Both algorithms have been tested using the same tunings for $i_{q}$ current controllers $\left(\mathrm{k}_{\mathrm{ipq}}=700, \mathrm{k}_{\mathrm{iiq}}=125000\right)$ and for flux controllers $\left(k_{\psi p}=200, k_{\psi i}=20000\right)$. The proportional gain of $i_{d}$ current controller in MTPASF was set to $\mathrm{k}_{\mathrm{ipd}}=700$. Under such tuning the compared algorithms have similar dynamic of flux and $\mathrm{i}_{\mathrm{q}}$-current control loops.

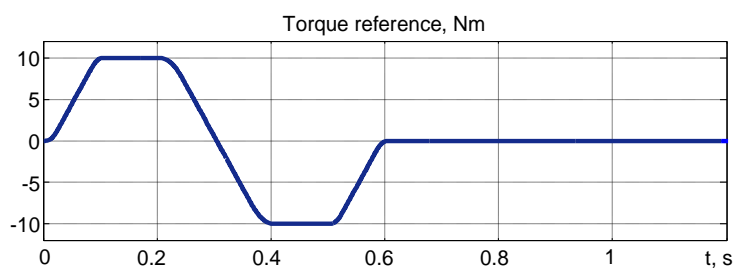

Fig. 10. Torque reference for DFVC and MTPASF

Fig.11 compares the transient behaviour of the DFVC in Fig.11a, as well as MTPASF with filtered static flux reference computation (28), (31) in Fig.11b, and with dynamic flux reference as (30) in Fig.11c. It can be concluded from Fig.11, that the stator current magnitude is the same for all compared algorithms in steady state. During dynamics, the DFVC algorithm (Fig. 11a) provides faster flux changes resulting in significant stator current spikes, in particular at zero torque crossings, when the flux is reduced to its minimum value.

In MTPASF with static flux reference formulation the desirable flux dynamic is defined by filter (31) coefficients hence can be adjusted as required. For example, the results 

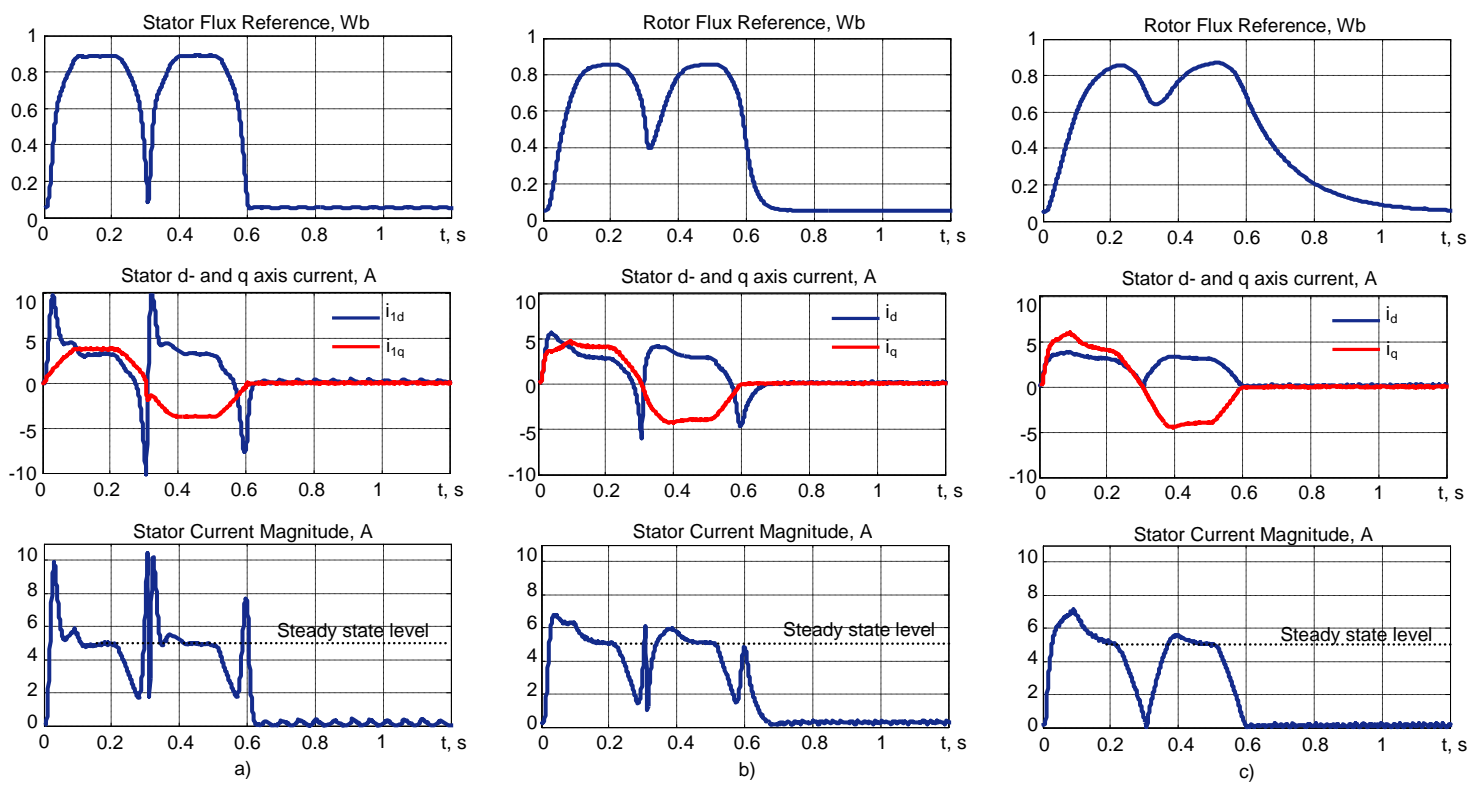

Fig. 11. Transients during tracking of smooth torque reference: a) DFVC; b) MTPASF with filtered static flux reference; c) MTPASF with dynamic flux reference

shown in Fig. $11 \mathrm{~b}$ are taken with $\mathrm{k}_{1}=130$, and $\mathrm{k}_{2}=4225$ providing natural frequency equal to $65 \mathrm{rad} / \mathrm{s}$. If the filter natural frequency is increased to $225 \mathrm{rad} / \mathrm{s} \quad\left(\mathrm{k}_{1}=450\right.$ and $\mathrm{k}_{2}=50625$ ), MTPASF provides the control dynamics similar to DFVC shown in Fig.11a. For MPTASF controller with dynamic flux reference (30) the transients are shown in Fig.11c from which it can be seen that smaller current magnitude is required to track the same torque trajectory. It should be noted that there are no current surges due the reduced rate of flux changes.

In addition, the effect of stator current increase during tracking of sinusoidal torque trajectories $\mathrm{T}^{*}=\mathrm{T}_{\mathrm{m}} \sin (2 \pi f t)$ is illustrated by experimentally-taken frequency responses shown in Fig.12. Maximum (peak) stator current as a function of the reference frequency is shown in Fig.12a, and the stator current meansquare value over the reference period - in Fig.12b. The characteristics were measured for two reference magnitudes: $\mathrm{T}_{\mathrm{m} 1}=4 \mathrm{Nm}(0.27 \mathrm{pu})$ и $\mathrm{T}_{\mathrm{m} 2}=8 \mathrm{Nm}(0.53 \mathrm{pu})$, and the current limitation has been set to $2 \mathrm{pu}$. As it is clearly seen, torque tracking of sinusoidal references using MTPASF with flux reference (30) requires smaller stator current at higher reference frequencies.

Note that further increase of torque reference frequency for MPTASF results in flux reference oscillating around the constant value with the small magnitude. Hence, this mean approaching the constant-flux operation. The frequency at which such quasi-constant-flux operation can be assumed is defined by the frequency response of the non-linear filter (30) hence depends on the machine parameters and on the torque reference magnitude $\left(\psi^{*}\right.$ that depends on $\mathrm{T}^{*}$ in the right-hand side denominator). As it was found for the employed machine, at $10 \mathrm{~Hz}$ torque reference the flux reference was oscillating within $4.5 \%$ of its steady-state value - this is small enough to consider this operational mode as a constant-flux mode.
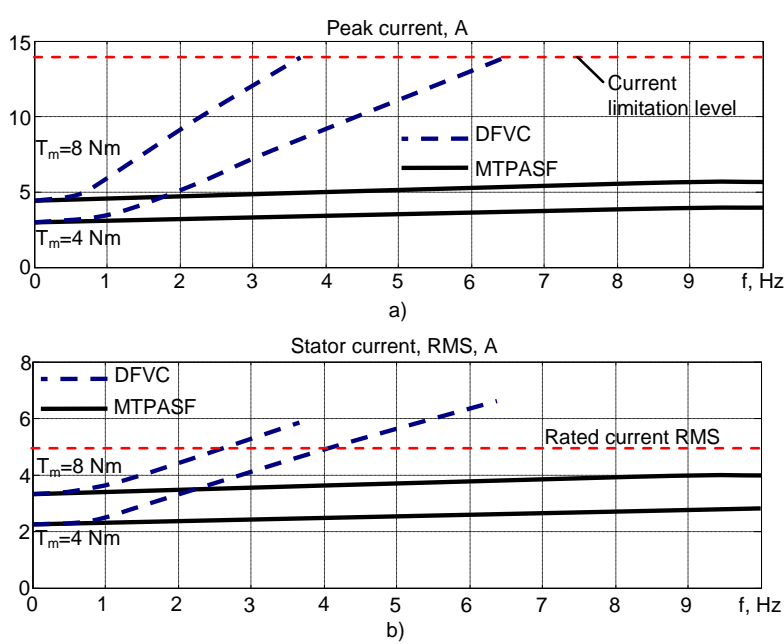

Fig. 12. Frequency responses of DFVC and MPTASF.

\section{CONCLUSIONS}

In this paper a novel MTPA field-oriented control algorithm for IM drives based on the output-feedback linearising technique has been designed and experimentally verified. The nonlinear controller guarantees asymptotic torque (speed) tracking of smooth reference trajectories and maximises the torque per Ampere ratio when the machine is operating with constant or slow varying torque. The two torque-flux controllers based on indirect and direct field orientation employing a reduced-order flux observer are designed. The torque-flux controllers and MTPA criterion take into consideration the effect of magnetic saturation in order to provide an improvement of the torque-flux tracking accuracy during the whole range of machine torques. Since the maximisation of torque per Ampere ratio is similar to the criterion of active losses minimisation, the machine efficiency at light loads is improved. The external speed tracking controller for the torque control system is designed and presented as well. The methodology of the flux reference calculation as static or dynamic function of the required torque is given, which allows to achieve MTPA optimisation in 
steady state, guarantees singularity free operation with small initial excitation for zero torque and can be used as mean to improve current transients.

An intensive experimental study of the proposed solution, and comparison against standard direct field-oriented control with constant flux operation, has proved that for the same torque and speed transient performances a significant stator current reduction is achieved in quasi steady-state operation. The effectiveness of the main flux saturation compensation is demonstrated experimentally. For faster torque references, experiments have proved that by appropriate flux reference selection one can achieve satisfactory stator current transients even for small initial flux excitation. The proposed IM drive control system is an attractive solution for technological applications where fast dynamic response is not required, for example in electric traction drives.

\section{APPENDIX I}

The first test rig was a Rapid Prototyping Station (RPS) as shown in Fig. A1. The RPS was based on a $5.5 \mathrm{~kW}$ induction motor, depicted as IM\#1 in Fig. A1, controlled by a 380V/50A PWM-inverter. The IM was mechanically coupled to a vector-controlled load machine. The Inverter switching frequency was $2.5 \mathrm{kHz}$. The motor speed and torque were measured by a 2500ppr optical encoder and a torque sensor (Lorenz Messtechnik DR-2). The sampling time was $100 \mu$ s.

IM \#1 technical characteristics: $P_{n}=5.5 \mathrm{~kW}, I_{n}=11 A, V_{n}=380 V$, $\mathrm{f}_{\mathrm{n}}=50 \mathrm{~Hz}, \omega_{\mathrm{n}}=150 \mathrm{rad} / \mathrm{s}, \mathrm{R}_{1}=0.94 \Omega, \mathrm{R}_{2}=0.65 \Omega, \mathrm{L}_{1 \sigma}=\mathrm{L}_{2 \sigma}=0.006 \mathrm{H}$, $\mathrm{L}_{\mathrm{m}}=0.117 \mathrm{H}$.

Controller parameters: $\quad \mathrm{k}_{\mathrm{ipd}}=\mathrm{k}_{\mathrm{ipq}}=700, \quad \mathrm{k}_{\mathrm{iiq}}=122500, \quad \gamma_{1}=8 \cdot 10^{-3}$, $\mathrm{k}_{1}=1000, \mathrm{k}_{2}=2.5 \cdot 10^{5}, \mathrm{k}_{\psi p}=30, \mathrm{k}_{\psi i}=450$.

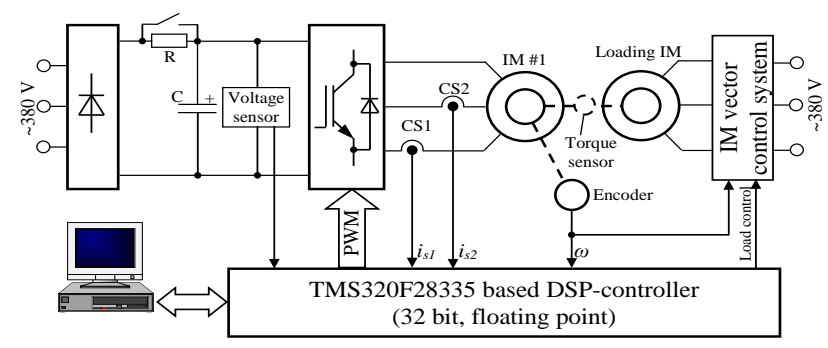

Fig. A1. Experimental setup of electromechanical system with testing and loading induction motors

\section{APPENDIX II}

The second test rig was based on a $50 \mathrm{~kW}$ induction motor powered by an industrial traction inverter and mechanically coupled to a DC machine load. The Inverter switching frequency was $2.5 \mathrm{kHz}$. The motor speed was measured by a $2500 \mathrm{p} / \mathrm{rev}$ optical encoder. The sampling time was $200 \mu \mathrm{s}$.

\section{0kW IM technical characteristics:}

$P_{n}=50 k W, I_{n}=98 A, V_{n}=380 V, f_{n}=50 H z, \omega_{n}=154 \mathrm{rad} / \mathrm{s}, R_{1}=0.15 \Omega$, $\mathrm{R}_{2}=0.04 \Omega, \mathrm{L}_{1 \sigma}=\mathrm{L}_{2 \sigma}=0.0015 \mathrm{H}, \mathrm{Lm}$ is given by Fig. 2 .

Controllers parameters: $\mathrm{k}_{\mathrm{ipd}}=\mathrm{k}_{\mathrm{ipq}}=500, \mathrm{k}_{\mathrm{iiq}}=62500, \gamma_{1}=10^{-3}, \mathrm{k}_{1}=1000$, $\mathrm{k}_{2}=2.5 \cdot 10^{5}$.

\section{APPENDIX III}

\section{$2.2 \mathrm{~kW}$ IM technical characteristics:}

$\mathrm{P}_{\mathrm{n}}=2.2 \mathrm{~kW}, \mathrm{I}_{\mathrm{n}}=5.0 \mathrm{~A}, \mathrm{~V}_{\mathrm{n}}=380 \mathrm{~V}, \mathrm{f}_{\mathrm{n}}=50 \mathrm{~Hz}, \omega_{\mathrm{n}}=151 \mathrm{rad} / \mathrm{s}, \mathrm{R}_{1}=3.5 \Omega$, $\mathrm{R}_{2}=2.5 \Omega, \mathrm{L}_{1 \sigma}=\mathrm{L}_{2 \sigma}=0.0091 \mathrm{H}, \mathrm{L}_{\mathrm{m}}=0.2709 \mathrm{H}$.

\section{REFERENCES}

[1] M.J.Melfi, S.Evon and R.McElveen, "Induction versus permanent magnets motors", IEEE Ind. Applicat. Magazine, vol. 15, pp. 28-35, Nov/Dec 2009.

[2] D.Biswas, K.Mukherjee and N.C.Kar "A Novel approach towards Electrical Loss Minimization in Vector Controlled Induction Machine Drive for EV/HEV" in Proc. 2012 Transportation Electrification Conference and Expo, 18-20 Jun., Dearborn, 2012, pp.1-5.

[3] W.Sung, J.Shin, and Y.Jeong, "Energy-Efficient and Robust Control for High-Performance Induction Motor Drive With an Application in Electric Vehicles" IEEE Trans. on Vehicular Technology, vol. 61, no. 8, pp. 3394-3405, 2012.

[4] B.K.Bose Modern power electronics and AC Drives, Upper Saddle River, NJ: Prentice Hall, 2002.

[5] J. Chiason Modelling and high performance control of Electrical Motors. IEEE Press, 2005.

[6] G. S. Buja and M. P. Kazmierkowski, "Direct torque control of PWM inverter-fed AC motors - a survey" IEEE Trans. on Industrial Electronics, vol. 51, no. 4, pp. 744-757, 2004.

[7] H.-T. Lee, Li-Ch. Fu and H.-S.Huang "Sensorless Speed Tracking of Induction Motor With Unknown Torque Based on Maximum Power Transfer" IEEE Trans. on Industrial Electronics, vol. 49, no. 4, pp. 911 924, 2002.

[8] A. M. Bazzi and P. T. Krein, "Review of methods for real-time loss minimization in induction machines," IEEE Trans. on Industry Applications, vol. 46, no. 6, pp. $2319-2328,2010$.

[9] Y. Wang, T. Ito, R. D. Lorenz, "Loss manipulation capabilities of deadbeat direct torque and flux control induction machine drives" IEEE Trans. on Industry Applications, vol. 51, no. 6, pp. 4554 - 4566, 2015.

[10] S. A. Odhano, R. Bojoi, A. Boglietti, Ş. G. Roşu, G. Griva "Maximum efficiency per torque direct flux vector control of induction motor drives" IEEE Trans. Industry Applications, vol. 51, no. 6, pp. $4415-$ 4424, 2015

[11] O.Wasynchuk, S.D.Sudhoff, K.A.Corsine, J.Tichenor, P.Krause, I.Hansen, L.Taylor "A maximum torque per Ampere control strategy for induction motor drives" IEEE Trans. on Energy Conversion, vol.13, no.2, pp.163-169, 1998 .

[12] S. N. Vukosavic, and E. Levi, "A Method for Transient Torque Response Improvement in Optimum Efficiency Induction Motor Drives” IEEE Trans. on Energy Conversion, vol. 18, no. 4, pp. $484-$ 493, 2003.

[13] J-F. Stumper, A. D“otlinger, and R. Kennel "Loss Minimization of Induction Machines in Dynamic Operation" IEEE Trans. on Energy Conversion, vol. 28, no. 3, pp. 726-735, 2013.

[14] A.Consoli, G.Scarcella, G.Scelba "Induction Motor Sensorless Control Based on a Maximum Torque per Ampere Approach” Record of the Industry Applications Conference, 2003. 38th IAS Annual Meeting. Conference, vol. 3, pp. 2005-2011.

[15] B.Grcar, P.Cafuta, G.Stumberger, A.M.Stankovic, A.Hofer "NonHolonomy in Induction Machine Torque Control" IEEE Trans. on Control Systems Technology, vol. 19, no. 2, pp. 367-375, 2011.

[16] M.Cacciato, A.Consoli, G.Scarcella, G.Scelba "Indirect Maximum Torque per Ampere Control of Induction Motor Drives" proc. of Power Electronics and Applications 2007, Aalborg, Denmark, pp. 1-10.

[17] C.Kwon and S.D.Sudhoff, "An improved maximum torque per amp control strategy for induction machine drives" in 20th Annual IEEE Applied Power Electronics Conference and Exposition, March, 2005, pp. 740-745.

[18] B.Gu, J.-Sh. Lai "Control of Induction Machine with Extended Range of Maximum Torque Capbility for Traction Drives" in Proc. 2011 Energy Conversion Congress and Exposition, 17-22 Sep., Phoenix, 2011, pp. 3590-3594.

[19] R.Bojoi, Z.Li, S.A.Odhano, G.Griva, A.Tenconi "Unified direct-flux vector control of induction motor drives with maximum torque per ampere operation" in Proc. 2013 Energy Conversion Congress and Exposition, 15-19 Sep., Denver, 2013, pp.3888-3895.

[20] G. Pellegrino, R. I. Bojoi, and P. Guglielmi, "Unified Direct-Flux Vector Control for AC Motor Drives," IEEE Trans. on Industry Applications, vol. 47, no. 5, pp. 2093-2102, 2011.

[21] S.Dymko, S.Peresada, R.Leidhold "Torque Control of Saturated Induction Motor with Torque per Ampere Ratio Maximization" in Proc. 2014 IEEE International Conference on Intelligent Energy and Power Systems, 2-6 Jun., Kyiv, 2014, pp.251-256. 
[22] Bozhko S, Dymko S, Kovbasa S, Peresada S, editors. MTA control for traction IM drives: Theory and experimental results. 2015 International Conference on Electrical Systems for Aircraft, Railway, Ship Propulsion and Road Vehicles (ESARS); 2015 3-5 March 2015.

[23] E.Levi "A Unified Approach to Main Flux Saturation Modelling in DQ Axis Models of Induction Machines" IEEE Trans. on Energy Conversion, vol. 10, no. 3, pp. 455-461, 1995.

[24] E.Levi "Impact of Cross-Saturation on Accuracy of Saturated Induction Machine Models" IEEE Trans. on Energy Conversion, vol. 12, no. 3, pp. 211-216, 1997.

[25] S.Peresada and A.Tonielli, "High-performance robust speed-flux tracking controller for induction motor," Int. J. Adapt. Control Signal Process., vol. 14, pp. 177-200, 2000.

[26] P.V.Kokotovic, H. K. Khalil and J.O'Reilly Singular Perturbation Methods in Control: Analysis and Design, Academic Press, 1987.

[27] P. V. Kokotovic, "The joy of feedback: nonlinear and adaptive", IEEE Control Systems Magazine, vol. 12. pp. 7-17, June 1992.

[28] Peresada S., Tilli A. and Tonielli A. Theoretical and experimenta comparison of indirect field-oriented controllers for induction motors // IEEE Trans. on Power Electronics, vol. 18, no. 1. pp. 151-163, 2003.

[29] E. Levi, S. Vukosavic, V. Vuckovic "Saturation Compensation Schemes for Vector Controlled Induction Motor Drives" in Proc. 21st Annual IEEE Power Electronics Specialists Conference, 11 - 14 Jun., San Antonio 1990, pp. 591 - 598

[30] S.Peresada, A.Tilli and A.Tonielli "New passivity based speed-flux tracking controllers for induction motor" in Proc. 2000 IEEE IECON Annual Conf. of the IEEE Industrial Electronics Society, Nagoya, 2000, pp. 1099-1104 